\title{
THE NATURE OF THE OBSTRUCTIVE MUSCULAR BUNDLES IN DOUBLE-CHAMBERED RIGHT VENTRICLE
}

Carlos Alva, MD

Siew Yen $\mathrm{Ho}, \mathrm{PhD}^{\mathrm{a}}$

Christopher R. Lincoln, FRCS ${ }^{\mathrm{a}}$

Michael L. Rigby, MD

Andrew Wright, MSc ${ }^{\mathrm{b}}$

Robert H. Anderson, MD
Objective: Our goal was to establish the morphologic nature of the obstructive muscular lesions in double-chambered right ventricle. Methods: We based our morphologic observations on 10 normal hearts and on the surgical findings in 26 patients, aged 0.5 to 24 years, with a mean of 6.9 years (SD 5.8 years). In the normal hearts, we measured the distance from the pulmonary valve to the apex of the right ventricle and from the takeoff of the moderator band to the ventricular apex. From angiograms available in $\mathbf{2 0}$ patients, using the frontal view, we then measured the distance from the pulmonary valve to the apex of the right ventricle and from the midpoint of the obstructive lesion to the apex of the right ventricle. This permitted calculations of multiple ratios. Results: In the 10 normal hearts, the moderator band took origin at a mean ratio of 0.48 (SD 0.16 ) of the ventricular length. On the basis of the angiographic findings, we identified 2 basic forms of double-chambered right ventricle. In 9 patients, the obstructive muscular shelf was positioned low and diagonally across the apical component, with a mean ratio of 0.38 relative to the ventricular length (SD 0.02 ). In the other 11 patients, the obstructive shelf was high and horizontal, with a mean ratio of 0.27 (SD 0.02). The difference was statistically significant $(P=$ $.001)$. Surgical repair was performed successfully in all 26 patients through a right ventriculotomy. Conclusions: Double-chambered right ventricle is the consequence of a high or low muscular division of the apical component of the right ventricle. The abnormal muscular bundle probably represents accentuated septoparietal trabeculations, rather than always being an abnormal moderator band. (J Thorac Cardiovasc Surg 1999;117:1180-9)
A bnormal compartmentalization of the morphologically right ventricle has been recognized since at least $1867 .{ }^{1}$ The morphology of the divided ventricle, however, remains controversial. During its existence,

From Paediatrics, National Heart and Lung Institute, Royal Brompton Campus, Imperial College School of Medicine, ${ }^{\mathrm{a}}$ and the Clinical Trials and Evaluation Unit, Royal Brompton Hospital, ${ }^{\mathrm{b}}$ London, United Kingdom.

Professor Anderson and Dr Ho are supported by the British Heart Foundation and the Joseph Levy Foundation. Dr Carlos Alva was a visiting research fellow from Hospital de Cardiologia Centro Medico Nacional Siglo XXI, Mexico City, Mexico.

Received for publication Aug 25, 1998; revisions requested Dec 11, 1998; revisions received Jan 20, 1999; accepted for publication Feb 26, 1999.

Address for reprints: R. H. Anderson, Paediatrics, National Heart and Lung Institute, Royal Brompton Campus, Imperial College School of Medicine, Dovehouse St, London SW3 6LY, United Kingdom

Copyright (C) 1999 by Mosby, Inc.

$0022-5223 / 99 \$ 8.00+0 \quad \mathbf{1 2 / 1 / 9 8 2 2 5}$ the malformation has been variously called cor triventriculare, anomalous muscle bundle of the right ventricle, development of right ventricular aberrant muscular bands, double-chambered right ventricle, right ventricular muscle band, aberrant muscle bundle of the right ventricle, obstructing muscle bands of the right ventricle, and divided right ventricle. ${ }^{2-9}$ A plethora of reports have been published since Tsifutis and associates, ${ }^{10}$ along with Lucas and colleagues, ${ }^{3}$ revived interest in the lesion in the 1960s. Different mechanisms have been proposed to explain the origin and nature of the obstruction. ${ }^{3,11,12}$ Most recently, Wong and colleagues ${ }^{13}$ suggested that the degree of superior displacement of the moderator band may help to identify those infants at risk for the development of subpulmonary obstruction. The problem with this suggestion, however, is agreeing on the nature and location of the moderator band and whether this structure truly forms the obstructing lesion. 


High horizontal obstruction
\begin{tabular}{|l|l|l|l|}
\hline Patient & $\begin{array}{l}\text { PV - } \Delta \\
(\text { C high })\end{array}$ & $\begin{array}{c}\text { PV-Apex } \\
(\text { a })\end{array}$ & Ratio \\
\hline$\# 4$ & 46 & 149 & 0.3 \\
\hline$\# 8$ & 39 & 146 & 0.26 \\
\hline$\# 10$ & 40 & 133 & 0.3 \\
\hline$\# 13$ & 40 & 150 & 0.26 \\
\hline$\# 14$ & 41 & 143 & 0.28 \\
\hline$\# 17$ & 37 & 140 & 0.26 \\
\hline$\# 19$ & 42 & 143 & 0.29 \\
\hline$\# 21$ & 39 & 144 & 0.27 \\
\hline$\# 22$ & 40 & 143 & 0.27 \\
\hline$\# 24$ & 37 & 142 & 0.26 \\
\hline$\# 25$ & 36 & 143 & 0.25 \\
\hline Mean & 39.7 & 143.3 & 0.27 \\
\hline SD & 2.76 & 4.52 & 0.02 \\
\hline
\end{tabular}

Low oblique obstruction
\begin{tabular}{|l|l|l|l|}
\hline Patient & $\begin{array}{c}\text { PV - A } \\
(\text { C low })\end{array}$ & $\begin{array}{c}\text { PV - Apex } \\
(\mathrm{a})\end{array}$ & Ratio \\
\hline$\# 2$ & 57 & 140 & 0.40 \\
\hline$\# 3$ & 59 & 151 & 0.39 \\
\hline$\# 5$ & 56 & 144 & 0.38 \\
\hline$\# 7$ & 51 & 148 & 0.34 \\
\hline$\# 9$ & 55 & 146 & 0.37 \\
\hline$\# 11$ & 59 & 148 & 0.39 \\
\hline$\# 12$ & 57 & 146 & 0.39 \\
\hline$\# 15$ & 52 & 142 & 0.36 \\
\hline$\# 23$ & 58 & 140 & 0.41 \\
\hline Mean & 56 & 145 & 0.38 \\
\hline SD & 2.87 & 3.81 & 0.02 \\
\hline
\end{tabular}

Measurements in $\mathrm{mm}, \mathrm{SD}=$ Standard deviation $\mathrm{PV}=$ pulmonary valve
Angiocardiographic measurements in patients with double chambered right ventricle

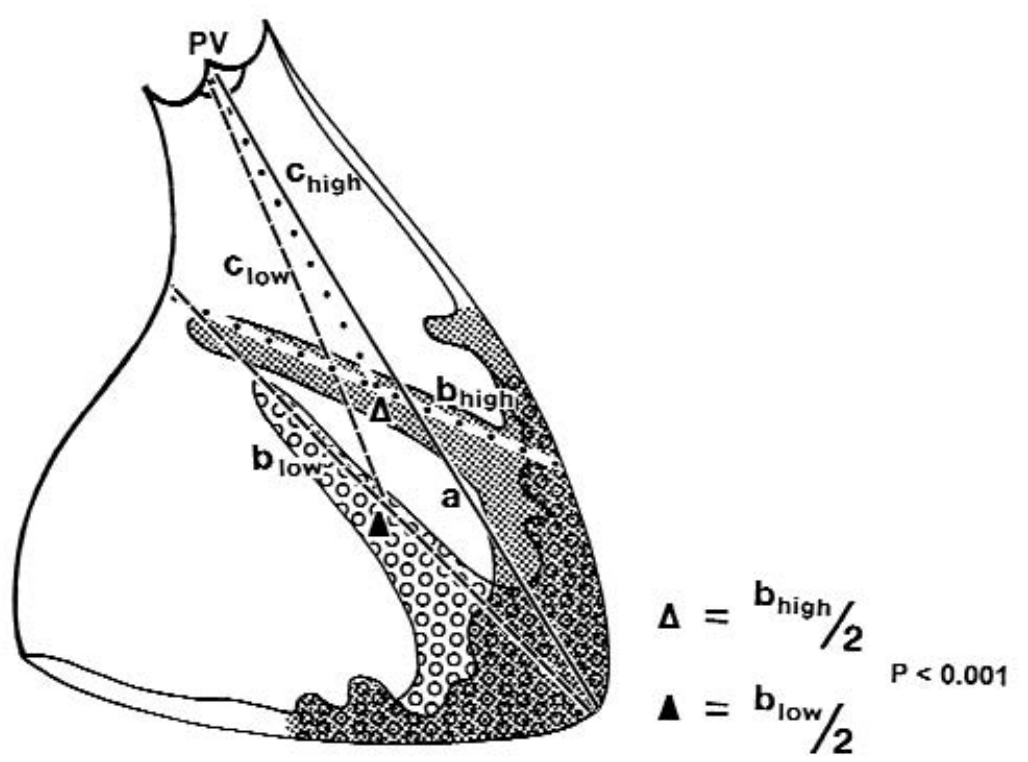

Fig 1A. The measurements made on the frontal views of the right ventriculogram. The two types of obstructive shelves (high and low) have been superimposed on the same outline. The solid line (a) represents the distance between the pulmonary valve and the apex of the right ventricle. The dotted line ( $b$ high) marks the level of the high obstructive shelf, while the broken line indicates the level of the low obstructive shelf ( $b$ low). So as to produce uniformity, we measured from the midpoints of these lines to create our ratios.

The entity is usually accompanied by a ventricular septal defect, but other widely described associations include discrete subaortic stenosis, ${ }^{14}$ valvular pulmonary stenosis, ${ }^{15}$ Ebstein's malformation, tetralogy of Fallot, ${ }^{9}$ and double-outlet right ventricle. ${ }^{11}$ It is the relationship with tetralogy of Fallot that is of particular significance, because the subpulmonary infundibulum itself is often sequestrated in tetralogy as a discrete smooth-walled chamber distal to the constriction between the muscular outlet septum and the hypertrophied septoparietal trabeculations. This infundibular stenosis, however, can coexist in a small proportion of patients with further muscular obstruction within the apical trabecular component of the right ventricle. ${ }^{16}$ The purpose of our review, therefore, was to study the nature of the spectrum of anomalous division of the morphologically right ventricle by correlating the morphologic, echocardiographic, and angiocardiographic findings with the direct observations made in a series of patients referred to one surgeon for intracardiac repair.

\section{Methods}

We analyzed first the structure of 10 normal autopsied hearts. By assessing the septal surface of the morphologically right ventricle, we made several measurements and ratios. First, we quantified the distance from the midpoint of the pulmonary valve to the apex of the ventricle. Along this axis, we then measured the distance from the pulmonary valve to the base of the muscular trabeculation deemed to represent the moderator band. This permitted calculations of the ratios of the location of the moderator band within the overall length of the right ventricle. On the basis of our direct morphologic observations, we then assessed the anatomic findings in 26 patients referred to one surgeon for correction of doublechambered right ventricle. In one of these patients, doublechambered right ventricle developed subsequent to correction of tetralogy of Fallot. We included all of the patients who had undergone surgical repair consecutively from 1980 to 1997 by a single surgeon (C.L.) working at the Royal Brompton Hospital. Previously, the site of the obstruction and a gradient had been documented between the components of the divided ventricle by cross-sectional echocardiography combined with Doppler interrogation or by cardiac catheterization. 


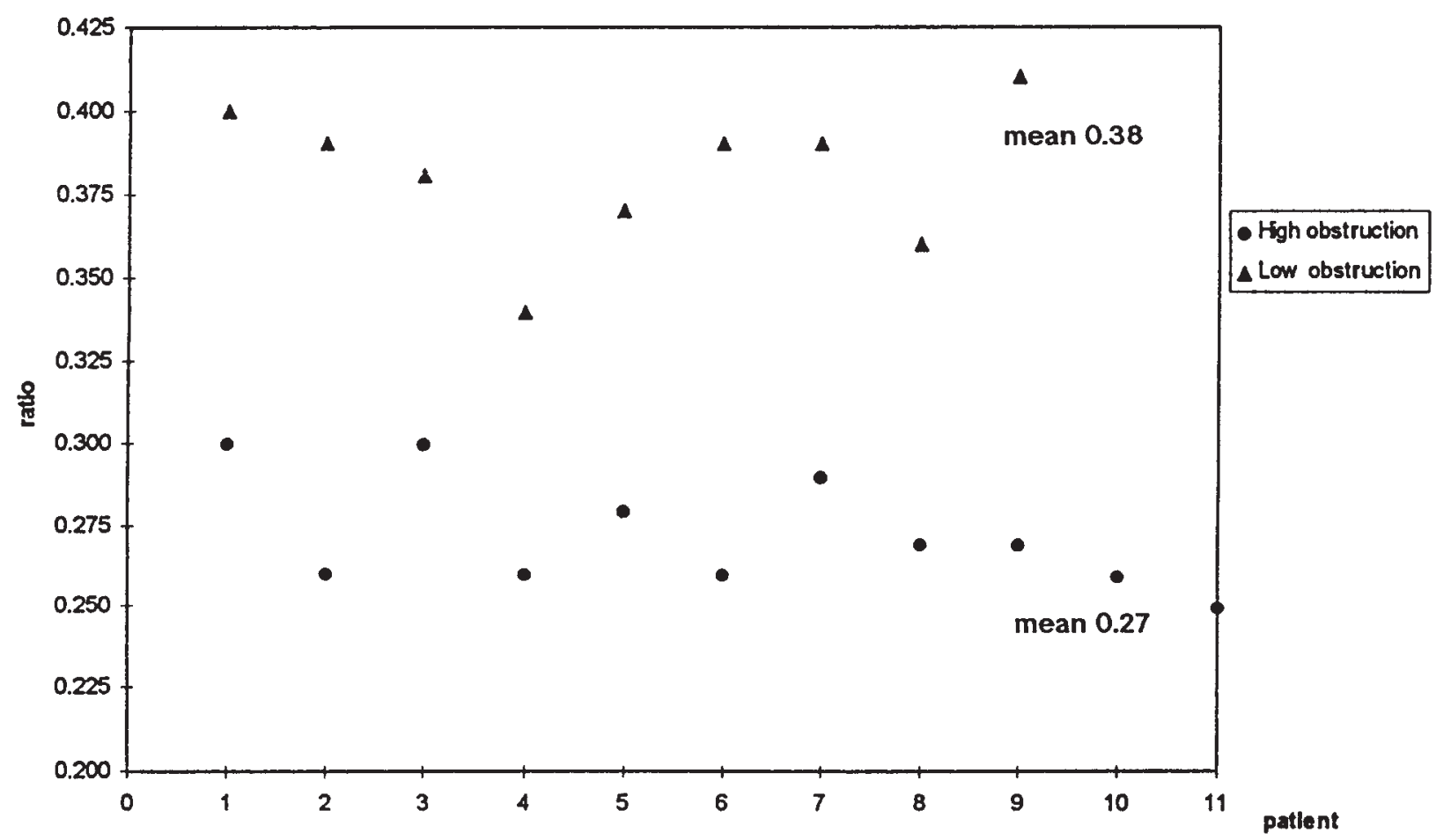

Fig 1B. There was a significant difference between the mean values of the high and low obstructions $(P=<.001)$.

Right ventricular angiography had revealed an obstructive filling defect below the level of the freestanding subpulmonary infundibulum, or else cross-sectional echocardiographic interrogation had demonstrated such obstruction below the level of the infundibulum of the right ventricle. In these patients, we analyzed the angiographic findings in the frontal view, assessing the site and extension of the division of the right ventricle. As with the normal hearts, we quantified the distance from the pulmonary valve to the apex of the right ventricle. A line was then drawn across the right ventricle along the plane of the obstructing lesion. We marked the midpoint of this line and measured the distance from it to the pulmonary valve in each patient (Fig 1A). This permitted calculation of the ratios of the distance of the site of the obstruction relative to the overall right ventricular length. In all 26 patients, division of the right ventricle had been confirmed by direct observation during the intracardiac repair. The clinical profile, echocardiographic studies, cardiac catheterization, angiograms, and surgical outcome were all reviewed.

Statistical analysis. Analysis of variance was used to determine whether the mean ratio, defined as the distance of the moderator band relative to the overall right ventricular length in the normal hearts and the distance of the site of obstruction relative to the overall right ventricle in the patients, differed between them. We compared 3 orthogonal contrasts. The normality of the residuals was checked by means of graphic methods, and Barlett's test was used to test the equal variance assumption. Nonparametric methods (the Kruskal-Wallis and Wilcoxon rank-sum tests) were also per- formed to assess the robustness of the conclusions of the parametric methods. All statistical analysis was performed with the STATA software package (Stata Corporation, College Station, Tex.).

\section{Results}

Normal hearts. The ventriculo-infundibular fold, freestanding infundibular sleeve, and the septomarginal trabeculation (septal band) were all readily identified in the normal hearts. It was also an easy matter in all the hearts to identify inlet, apical trabecular, and outlet components of the right ventricle (Figs 2 and 3). The prominent septomarginal trabeculation (septal band) overlaid the junction of these components immediately beneath the ventriculo-infundibular fold, the latter structure representing the inner heart curvature. When traced toward the apex, the septomarginal trabeculation ramified to become continuous with the major papillary muscles. One band usually took a characteristic course to join the anterior papillary muscle. This structure is known as the moderator band (Fig 2), but its presence and location are far from uniform. It was absent in 2 of the normal hearts. Furthermore, in all the normal hearts, several other prominent septoparietal trabeculations were found extending from the anterior margin of the septomarginal trabeculation to the pari- 


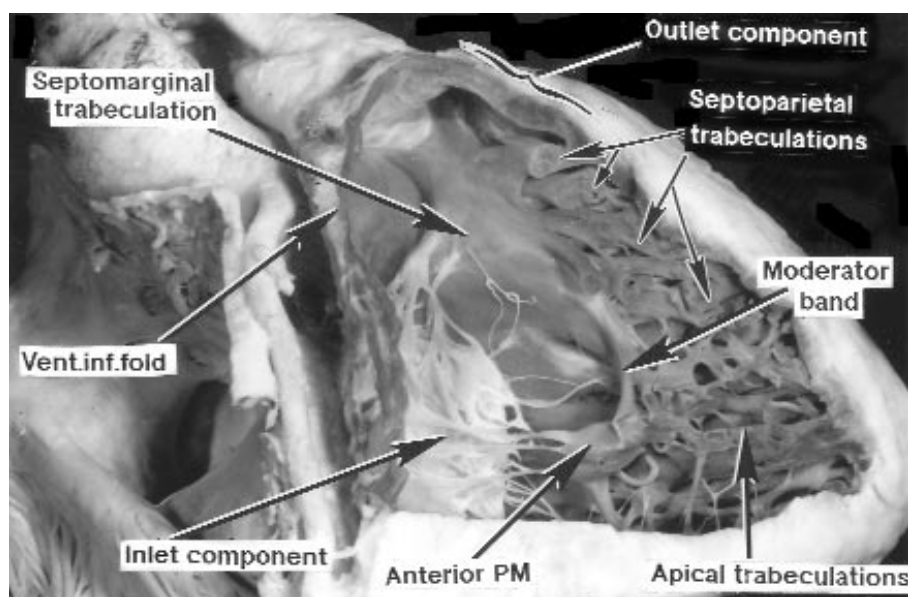

Fig 2. In this normal heart, the 3 components of the right ventricle are well seen. Note the septomarginal trabeculation along with a distinctive muscular band, the moderator band, joining the anterior papillary muscle $(P M)$. Multiple apical and septoparietal trabeculations are also seen. Vent.inf.fold, Ventriculo-infundibular fold.

etal wall. From 4 to 7 of these septoparietal trabeculations were found in the overall series, with a mean of 5.3. Along with these major septoparietal trabeculations, multiple minor trabeculations extended to the apex, creating complex but variable patterns of trabeculations within the apical component of the right ventricle (compare Figs 2 and 3).

Within the series of these normal hearts, the mean distance from the pulmonary valve to the origin of the moderator band, or to the most prominent septoparietal trabeculation in the 2 hearts without a moderator band, relative to the overall length of the right ventricle yielded a mean ratio of 0.48 (SD 0.16).

Clinical findings. The ages of the patients undergoing surgical repair ranged from 0.5 to 24 years, with a median of 5.8 and a mean of 6.9 years (SD 5.8 years). The atrial chambers were arranged in a solitus position in 24 patients and were mirror-imaged (inversus) in 1. The atrioventricular and ventriculo-arterial connections were concordant in all. A perimembranous ventricular septal defect was present in 18 patients (72\%), 12 being considered small and 6 large. Ventricular septal defects had been documented previously in at least 2 other patients. No symptoms had been reported by 16 (64\%) of the patients, although breathlessness on effort was present in $8(32 \%)$, and $3(12 \%)$ patients had mild cyanosis.

Echocardiography and cardiac catheterization (Table I). Cross-sectional echocardiography, with Doppler and color Doppler interrogation, had been performed in 20 patients. Anomalous bundles were observed arising perpendicular to the ventricular sep-

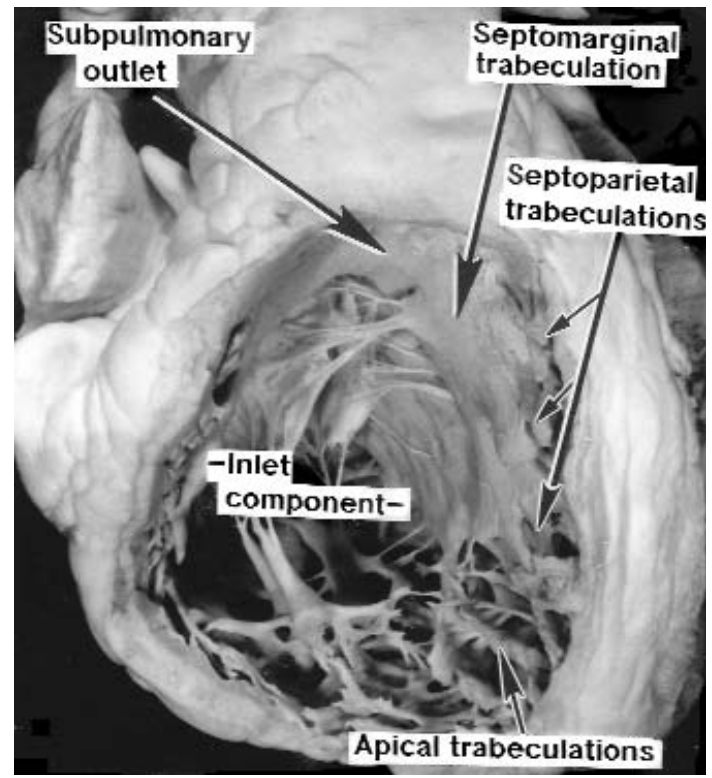

Fig 3. Another normal heart. It is again easy to identify the 3 components of the right ventricle. A discrete moderator band was not found, but multiple muscular septoparietal trabeculations were associated with a uniform pattern of coarse apical trabeculations.

tum and crossing the cavity in either the oblique or horizontal fashion (Figs 4, $A$ and 5, $A$ ). The severity of the stenosis between the 2 chambers could be assessed with Doppler echocardiography. Care was needed not to mistake the systolic jet of a ventricular septal defect from that resulting from the obstruction within the ven- 
Table I. Clinical investigations

\begin{tabular}{|c|c|c|c|c|}
\hline $\begin{array}{c}\text { Patient } \\
\text { No. }\end{array}$ & $\begin{array}{l}\text { Age } \\
(y)\end{array}$ & $\begin{array}{l}\text { Systolic } \\
\text { pressure, } \\
\text { RV cath. } \\
(\mathrm{mm} \mathrm{Hg})\end{array}$ & $\begin{array}{c}\text { Gradient, } \\
\text { cardiac cath. } \\
\text { (mm Hg) }\end{array}$ & $\begin{array}{l}\text { Echo- } \\
\text { Doppler } \\
\text { gradient } \\
\text { (mm Hg) }\end{array}$ \\
\hline 1 & 1.16 & 130 & 110 & 120 \\
\hline 2 & 5 & 90 & 56 & \\
\hline 3 & 3 & 67 & 54 & 70 \\
\hline 4 & 8 & 82 & 49 & 60 \\
\hline 5 & 15 & 90 & 65 & \\
\hline 6 & 24 & 100 & 85 & \\
\hline 7 & 13 & 63 & 40 & 63 \\
\hline 8 & 2.5 & 58 & 32 & 40 \\
\hline 9 & 5.8 & 100 & 52 & 100 \\
\hline 10 & 1.75 & 85 & 65 & 70 \\
\hline 11 & 6.41 & 117 & 73 & 80 \\
\hline 12 & 6.16 & 70 & 40 & 60 \\
\hline 13 & 8.8 & 75 & 50 & 60 \\
\hline 14 & 2.25 & & & 50 \\
\hline 15 & 5.5 & 76 & 53 & 63 \\
\hline 16 & 14 & & & 80 \\
\hline 17 & 1.75 & 40 & 24 & 50 \\
\hline 18 & 8.5 & 83 & 56 & \\
\hline 19 & 0.5 & 135 & 107 & 150 \\
\hline 20 & 10 & 70 & 52 & 100 \\
\hline 21 & 1.16 & 75 & & \\
\hline 22 & 16 & 78 & 43 & 63 \\
\hline 23 & 7 & 80 & 52 & 61 \\
\hline 24 & 2 & & & 70 \\
\hline 25 & 2.58 & 65 & 17 & 40 \\
\hline Mean & 6.9 & 83.1 & 56.0 & 72.5 \\
\hline SD & 5.8 & 23 & 23 & 27.1 \\
\hline Median & 5.8 & 79 & 52 & 63 \\
\hline
\end{tabular}

Cath., Catheterization; SD, standard deviation.

tricle. The continuous Doppler gradient measured between the 2 components of the right ventricle ranged from 40 to $150 \mathrm{~mm} \mathrm{Hg}$, with a median of $63 \mathrm{~mm} \mathrm{Hg}$. The diagnosis had been predicted in 19 patients and suspected in the other. In the last 2 years, 3 patients have undergone surgical correction without cardiac catheterization.

Cardiac catheterization and selective angiography was performed in 22 patients. The anomalous muscular bundles, as seen in anteroposterior projection, took the form of 1 or more filling defects that crossed the right ventricular cavity either diagonally (Fig 4, B) or almost horizontally (Fig 5, B). In the most severe forms, the obstruction was seen as a pyramidal filling defect, with its base broadly attached to the anterior ventricular wall and with the apex protruding superiorly. The measured peak proximal systolic pressure ranged from 40 to 135 $\mathrm{mm} \mathrm{Hg}$, with a mean of $79 \mathrm{~mm} \mathrm{Hg}$. A gradient, measured in 21 patients, ranged from 17 to $110 \mathrm{~mm} \mathrm{Hg}$, with a mean of $52 \mathrm{~mm} \mathrm{Hg}$.
Table II. Angiocardiographic ratios in patients with double-chambered right ventricle

\begin{tabular}{ll}
\hline Patient No. & PV-obstruction/PV-apex RV ratio \\
\hline High horizontal obstruction & \\
4 & 0.3 \\
8 & 0.26 \\
10 & 0.3 \\
13 & 0.26 \\
14 & 0.28 \\
17 & 0.26 \\
19 & 0.29 \\
21 & 0.27 \\
22 & 0.27 \\
24 & 0.26 \\
25 & 0.25 \\
Mean & 0.27 \\
SD & 0.02 \\
Low oblique obstruction & \\
2 & 0.40 \\
3 & 0.39 \\
5 & 0.38 \\
7 & 0.34 \\
9 & 0.37 \\
11 & 0.39 \\
12 & 0.39 \\
15 & 0.36 \\
23 & 0.41 \\
Mean & 0.38 \\
SD & 0.02 \\
\hline P &
\end{tabular}

$P V$, Pulmonary valve; $R V$, right ventricular; $S D$, standard deviation.

Double-chambered right ventricle associated with tetralogy of Fallot. Double-chambered right ventricle was discovered 10 years subsequent to radical correction of tetralogy in one 24-year-old man. The echoDoppler study demonstrated a gradient of $100 \mathrm{~mm} \mathrm{Hg}$ across the obstructive lesion. The right ventricular angiogram confirmed the presence of an anomalous horizontal muscular shelf within the apical component of the ventricle, positioned just below the smooth infundibulum.

Angiocardiographic and morphologic correlations. In 20 of the 22 patients undergoing angiocardiography, it proved possible to make accurate measurements by using the frontal projections. These measurements showed that, in our patients, doublechambered right ventricle occurred in 2 basic forms. In 9 patients, the muscular shelf was positioned diagonally and low across the apical component of the right ventricle (Fig 4). In these patients, the mean distance from the pulmonary valve to the midpoint of the plane of obstruction, when calculated relative to the mean value of the overall length of the right ventricle, produced a mean ratio of 0.38 (SD 0.02) (Table II). In the 

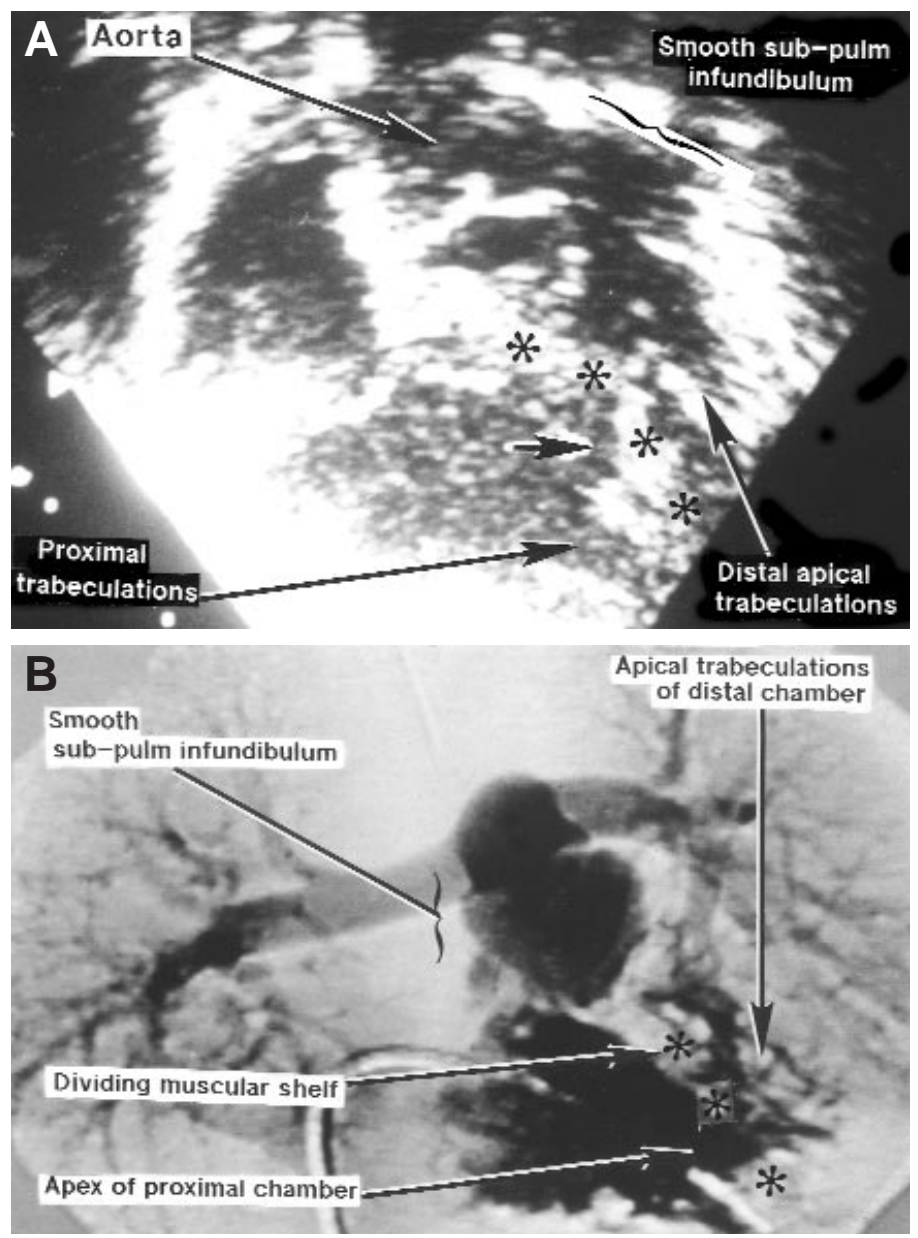

Fig 4. An echocardiographic subcostal right anterior oblique view (A) shows an anomalous muscular shelf crossing the right ventricle obliquely (asterisks), producing severe obstruction (arrow) between the 2 chambers. The right ventriculogram (B) confirms the diagonal and low position of the anomalous muscular bundle (asterisks) and reveals the narrow channel between the 2 chambers. Measurements (Fig 1) revealed significant differences between the location of the lesion shown in this figure as compared with Fig 5.

remaining 11 patients, however, the obstructing lesion was positioned high and horizontally (Fig 5). In these patients, the mean ratio was 0.27 (SD 0.02) (Table II). When we compared the mean ratio of the patients with low obstruction $(0.38, \mathrm{SD} 0.02)$ and the mean ratio of patients with high obstruction $(0.27, \mathrm{SD} 0.02)$, the ratio was significantly less with high obstruction $(P=.001)$ (Fig 1, B). Furthermore, testing the comparison of the mean ratio obtained for the location of the moderator band of the normal hearts with the location of the obstructive shelf in patients with either high or low obstruction was statistically significant $(P=.001)$. The mean ratio for the patients with double-chambered right ventricle was $35 \%$ less than the mean ratio for normal hearts (95\% confidence interval 21\%-54\%).
The moderator band in normal hearts, therefore, is situated in a different position from the obstruction found in patients with double-chambered right ventricle.

Surgical findings and outcome. Operative repair was performed in all 26 patients through a right ventriculotomy. The most common finding, as seen through the ventriculotomy, was the presence of an abnormal shelf of muscle taking origin at different levels from the body of the septomarginal trabeculation. This finding was described in 17 patients (65\%). Muscular bundles were found crossing the apical component of the right ventricle in $5(19 \%)$, and a solitary muscular bar was described in the other 4 (15\%). Right ventriculotomy served well in our series to provide access for resection of the muscular shelf. The anom- 

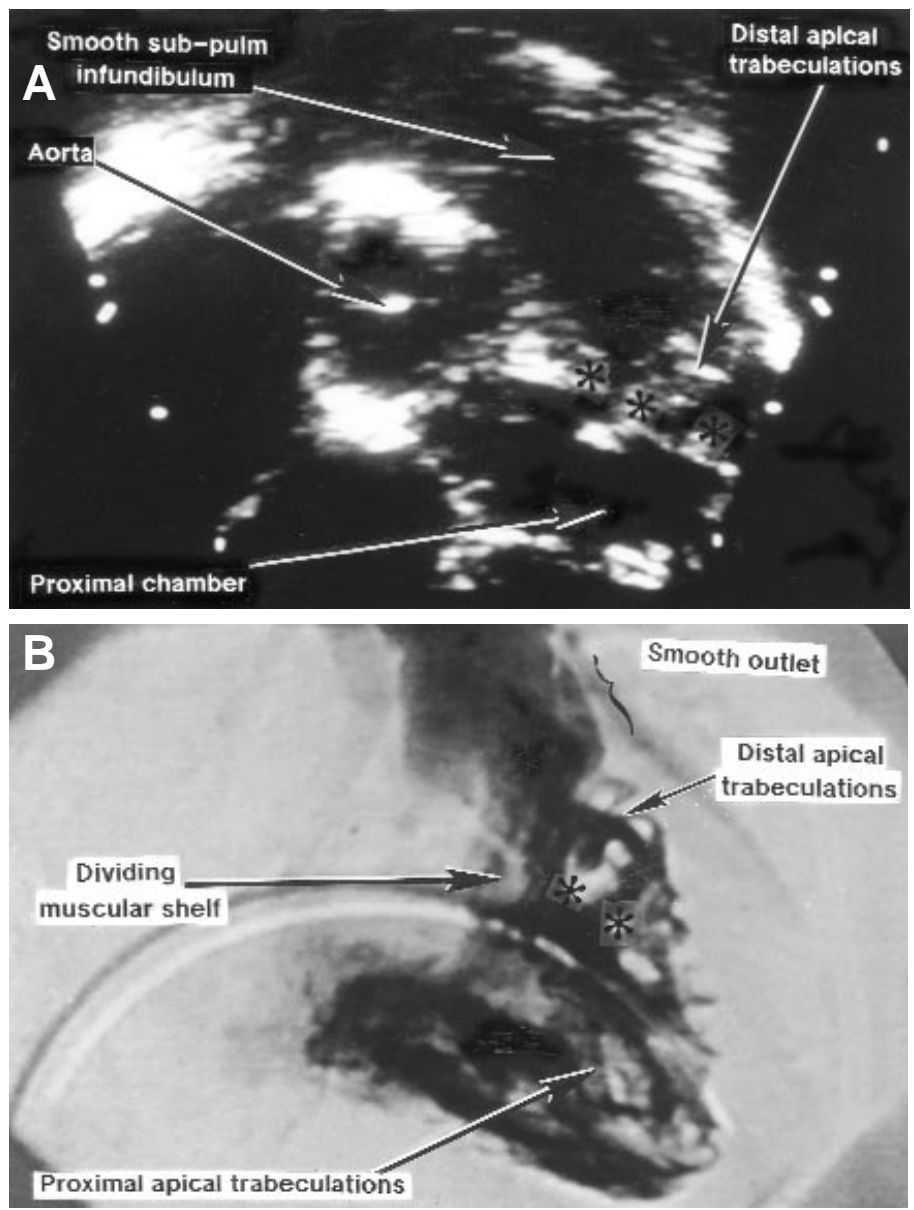

Fig 5. An echocardiographic subcostal right anterior oblique view (A) shows an anomalous muscular shelf crossing the right ventricle high and horizontally (asterisks), producing severe obstruction between the 2 chambers. The right ventriculogram (B) confirms the high and almost horizontal position of the anomalous muscular bundle (asterisks) and reveals the narrow channel between the 2 chambers. Measurements (Fig 1) revealed significant differences between the location of the lesion shown in this figure as compared with Fig 4.

alous muscle bundles were transected from the septum and from their parietal attachments, taking care not to damage the tricuspid valve. Inspection was always made to exclude a ventricular septal defect, even if such a communication had not been diagnosed before the operation. A perimembranous septal defect had been closed in 18 patients (69.2\%). In 5 of these (27\%), the ventricular septal defect had opened to the distal part of the divided ventricle. Neither early nor late mortality was recorded. Twelve patients (46\%) were noted postoperatively to have incomplete right bundle branch block. All the patients were seen subsequently in the outpatient clinic, with no significant gradient (less than $20 \mathrm{~mm} \mathrm{Hg}$ or no gradient) being found at echocardiographic examination at least 1 year after the operation.

\section{Discussion}

So far as we know, Peacock ${ }^{1}$ was the first to describe double- chambered right ventricle as a "constriction of the first portion of the right ventricular infundibulum." The nature of the obstructive anomalous muscle structures was then the subject of discussion in Keith's account ${ }^{17}$ of right ventricular abnormalities. Over the subsequent years, however, there has been no consensus about the origin of the anomalous bundles. ${ }^{3,6,12}$ Our own observations show that the typical form of doublechambered right ventricle is best interpreted on the basis of anomalous division within the apical trabecular component. In the normal heart, the subpulmonary infundibulum can be readily distinguished on the basis of its smooth wall, which forms a complete muscular 
sleeve supporting the leaflets of the pulmonary valve. Proximal to the infundibulum, the septal surface of the normal ventricle is characterized by a prominent strap, the septal band, or septomarginal trabeculation. From the anterior surface of this strap arise a series of muscular bundles, named by Goor and Lillehei ${ }^{18}$ as septoparietal trabeculations. In addition to these serried trabeculations running to the parietal ventricular wall, an additional prominent muscle bar runs to the anterior papillary muscle. It is this muscle extending to the papillary muscle that is traditionally described as the moderator band, since its action was initially considered to moderate the action of the tricuspid valve. ${ }^{19}$ This band, in the normal heart, is often smaller than the most prominent of the septoparietal trabeculations. Furthermore, the origin of the moderator band itself shows marked variation within the extent of the normal right ventricle.

The anomalous obstructive muscular lesion identified in our population of patients was, in the majority, a muscular shelf originating from the body of the septomarginal trabeculation and extending toward the ventricular apex. Measurements of our angiograms then revealed 2 discrete and statistically significantly different locations for this muscular shelf. A low and oblique partition was identified in 14 (54\%) of the patients, with 3 of these having additional obliteration of the apex of the right ventricle by muscular overgrowth. In contrast, the shelf was positioned high and horizontally in $12(46 \%)$ of the patients. Irrespective of its location, the 2 parts of the right ventricle to either side of the shelf each possessed part of the apical ventricular component, with the trabeculated proximal chamber in continuity with the ventricular inlet, and the distal chamber, with its own coarse trabeculations, supporting the subpulmonary infundibulum. In none of the cases was the distal chamber confined to the smooth subpulmonary infundibulum, as is seen in tetralogy of Fallot. When the more typical division of the right ventricle, as presently described, is combined with double-outlet right ventricle, the proximal chamber can support one arterial root and the distal chamber gives rise to the other. As a variant of this particular combination, it is then known that division of the right ventricle can simulate "double-chambered left ventricle" should the ventricular septal defect open to the distal ventricular compartment. ${ }^{20}$ There are, of course, still further forms of division of the right ventricle, as was illustrated by Restivo and colleagues. ${ }^{9}$ All are readily explained on the basis of a tripartite formation of the normal right ventricle. Examples of these other variants are sequestration of the ventricular inlet portion, as occurs rarely in imperforate Ebstein's malformation, or sequestration of the subpulmonary infundibulum, as already discussed for tetralogy of Fallot. The very coexistence of tetralogy with double-chambered right ventricle, shown recently to occur in $3 \%$ of patients in one large series, ${ }^{16}$ points to the location of the obstructive muscular lesion within the apical trabecular component of the right ventricle. Regarding the nature of the lesions, nonetheless, suggestions that high takeoff of the moderator band is always the cause of the anomaly ${ }^{13}$ seem to oversimplify the anatomic spectrum. Furthermore, in our series, surgical division of the anomalous muscular bands did not always result in complete right bundle branch block, as would have been expected had the obstructive muscle indeed been the moderator band. In this respect, Byrum and colleagues ${ }^{21}$ performed elegant preoperative, intraoperative, and postoperative electrophysiologic studies in 7 patients with double-chambered right ventricle showing that ventricular activation was normal after the operation. They, too, concluded that the moderator band was not the obstructing bundle, and in general we endorse their conclusion, although we cannot deny that some of the bundles might represent hypertrophied moderator bands.

Although the obstruction produced by the anomalous muscle is often progressive, ${ }^{12}$ such progression does not occur uniformly. ${ }^{22}$ Patients who do not have a pressure gradient in the setting of a small ventricular septal defect, or else only a small gradient, need not undergo immediate cardiac surgery. Such patients should be monitored with echocardiography. Only if the obstruction is shown to progress should they be referred for surgical repair. Recognition of this progression has led to suggestions that the malformation is an acquired lesion in the setting of deficient ventricular septation. ${ }^{13}$ Such a concept, however, is difficult to reconcile with the fact that our patient with the most severe obstruction, and also our youngest patient, aged 6 months, manifested the muscular obstruction when the ventricular septum was intact. In fact, obstruction develops within the right ventricle in only $3 \%$ of patients with deficient ventricular septation. ${ }^{23}$ Although the majority of patients do have a ventricular septal defect, other factors must be involved. An abnormal location of prominent septoparietal trabeculations, combined with acquired factors, seem to us to provide the best explanation for the complex morphology.

Right ventriculotomy served well in our series as the access for resection of the muscular shelf, but others have reported good results when approaching through a right atriotomy. ${ }^{24,25}$

In summary, therefore, we conclude that double-cham- 
bered right ventricle is a congenital cardiac malformation produced by abnormal division of the apical component of the right ventricle by accentuated septoparietal trabeculations. The lesion usually progresses with time, creating proximal high-pressure and low-pressure distal chambers. Surgical correction, with anticipated excellent results, is indicated when obstruction reaches $40 \mathrm{~mm} \mathrm{Hg}$ of gradient, or less if the obstruction is associated with a large ventricular septal defect.

We are grateful to Karen McCarthy, Zarlasht Najem, and Vi-Hue Tran for their excellent technical assistance and to Christine Anderson for expert secretarial help. We are also indebted to Professor A. N. Redington and Dr E. A. Shinebourne, who were involved in the clinical care of many of the patients studied.

\section{REFERENCES}

1. Peacock TB. Malformation of the human heart. London: Churchill and Sons; 1867. p. 75-9.

2. Walter DC, Wynter L. Cor triventriculare: infundibular stenosis with subdivision of the right ventricle. Br Heart J 1961;23:599602.

3. Lucas RV, Varco RL, Lillehei CW, et al. Anomalous muscle bundle of the right ventricle. Circulation 1962;25:443-55.

4. Hartman AF, Goldring D, Carlsson E. Development of right ventricular aberrant muscular bands. Circulation 1964;30:679-85.

5. Gale GE, Heimann KW, Barlow JB. Double-chambered right ventricle. Br Heart J 1969;31:291-8.

6. Forster JW, Humphries JD. Right ventricular anomalous muscle bundle: clinical and laboratory presentation and natural history. Circulation 1971;43:115-28.

7. Barnes RJ, Kwong KH, Cheung ACS. Aberrant muscle bundle of the right ventricle. Br Heart J 1971;33:546-51.

8. Fellows KE, Martin EC, Rosenthal A. Angiocardiography of obstructing muscular bands of the right ventricle. AJR Am J Roentgenol 1977;128:249-56.

9. Restivo A, Cameron AH, Anderson RH, Allwork SP. Divided right ventricle: a review of its anatomical varieties. Pediatr Cardiol 1984;5:197-204.

10. Tsifutis AA, Hartmann AF Jr, Arvidsson H. The two-chambered right ventricle: report on seven patients. Transactions of the Section on Cardiology, American Academy of Pediatrics 1961. p. 5.

11. Gallucci V, Scalia D, Thiene G, Mazzuco A, Valfre C. Doublechambered right ventricle: surgical experience and anatomical considerations. Thorac Cardiovasc Surg 1980;28:13-7.

12. Pongliglione G, Freedom RM, Cook D, Rowe RD. Mechanisms of acquired right ventricular outflow tract obstruction in patients with ventricular septal defect: an angiocardiographic study. Am J Cardiol 1982;52:776-80.

13. Wong PC, Sanders SP, Jonas RA, et al. Pulmonary valve-moderator band distance and association with development of doublechambered right ventricle. Am J Cardiol 1991;68:1681-6.

14. Kveselis D, Rosenthal A, Ferguson P, Behrendt D, Sloan H. Longterm prognosis after repair of double-chambered right ventricle with ventricular septal defect. Am J Cardiol 1984;54:1292-5.

15. Rowland TW, Rosenthal A, Castaneda AR. Double chamber right ventricle: experience with 17 cases. Am Heart J 1985;89:455-62.
16. Moran AM, Hornberger LK, Jonas RA, Keane JF. Development of a double-chambered right ventricle after repair of tetralogy of Fallot. J Am Coll Cardiol 1998;31:1127-33.

17. Keith A. The Hunterian Lectures on malformations on the heart. Lancet 1909;2:359.

18. Goor DA, Lillehei CW. The anatomy of the heart. In: Congenital malformations of the heart. New York: Grune \& Stratton; 1975. p. 11-6.

19. King TW. An essay on the safety valve function of the right ventricle. Guy Hosp Rep 1837;2:104.

20. Beitzke A, Anderson RH, Wilkinson JL, Shinebourne EA. Twochambered right ventricle: simulating two-chambered left ventricle. Br Heart J 1979;42:22-6.

21. Byrum CJ, Dick M, Behrendt DM, Hees P, Rosenthal A. Excitation of the double chamber right ventricle: electrophysiologic and anatomic correlation. Am J Cardiol 1982;49:1254-8.

22. Simpson WF, Sade RM, Crawford FA, Taylor AH, Fyfe DA. Double-chambered right ventricle. Ann Thorac Surg 1987;44:710.

23. Weidman WH, Bloung GS Jr, DuShane SW, Gersony W, Hayes CS, Nadas AS. Clinical course in ventricular septal defect. Circulation 1977;56(Suppl):I56-69.

24. Cabrera A, Martinez P, Rumoroso JR, et al. Double-chambered right ventricle. Eur Heart J 1995;16:682-6.

25. Penkoske PA, Duncan N, Collins-Nakai RL. Surgical repair of double-chambered right ventricle with or without ventriculotomy. J Thorac Cardiovasc Surg 1987;93:385-93.

\section{Commentary}

In the article by Alva and associates, the authors report their institutional experience with double-chambered right ventricle over an 8-year period. This report serves to expand our knowledge on the morphologic nature of this entity. Their objective was to study the muscular division of the right ventricle by correlating morphologic, echocardiographic, and angiographic findings.

Double-chambered right ventricle, the partitioning of the right ventricle into 2 chambers, has been recognized since at least $1867^{1}$ and is produced by prominent anomalous muscle bundles within the right ventricular cavity. Although frequently associated with membranous ventricular septal defects, ${ }^{2}$ other anatomic forms have also been reported. ${ }^{3-5}$ Most recently, my colleagues and $\mathrm{I}^{6}$ reported our own institutional experience of the development of double-chambered right ventricle in postoperative patients with tetralogy of Fallot, with a minimal occurrence rate of $3.1 \%$. An underlying anatomic substrate was recently suggested by Wong and colleagues. ${ }^{7}$ They described the presence of a displaced insertion of moderator band into the septal band. This pattern of insertion was recognized both in pathologic specimens and in clinical cases. The evaluation in human beings used 2-dimensional echocardiographic methods. This displacement of the moderator band was further quantified as the distance of the 